\title{
Malformación congénita de la vía aérea pulmonar. Informe de un caso y revisión de la literatura
}

\author{
Dr. José David Palmer-Becerra *, Dr. Arturo Montalvo-Marín **, Dr. Hugo Uro-Huerta ***, \\ Dra. Silvia Gutiérrez-Lucatero *, Dr. Jorge Eduardo Madriñan-Rivas ****
}

\section{RESUMEN}

La malformación congénita de la vía aérea pulmonar es poco frecuente; se caracteriza por la presencia de una masa inmadura de tejido pulmonar con varios grados de cambios en las lesiones quísticas. Se diagnostica in utero por ultrasonido. Las manifestaciones clínicas varían desde dificultad respiratoria severa con muerte neonatal hasta lesiones asintomáticas. El tratamiento de elección es la resección quirúrgica por toracoscopia, método seguro con menor frecuencia de complicaciones postoperatorias.

Palabras clave: Malformación congénita de la vía aérea pulmonar, malformación adenomatoidea quística congénita, lesiones quísticas pulmonares, diagnóstico prenatal, resección toracoscópica.

\begin{abstract} with a lower incidence of postoperative complications. diagnosis, thoracoscopic resection.

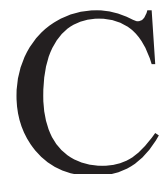
on el advenimiento del ultrasonido prenatal en la última década, ha sido posible diagnosticar lesiones pulmonares congénitas a partir de la semana 16 de gestación. Stocker, propone cambiar el término malformación adenomatoidea quísti-
\end{abstract}

Congenital pulmonary airway malformation is a rare condition characterized by the presence of an abnormal mass of immature malformed tissue with varying degrees of cystic changes. It is diagnosed prenatally by ultrasound scan. Postnatal presentation ranges from severe respiratory distress with neonatal death to asymptomatic lesions. Thoracoscopic surgical resection has shown to be safe and associated

Key words: Congenital pulmonary airway malformation, congenital cystic adenomatoid malformation, congenital lung lesions, prenatal

* Cirugía Pediátrica

** Profesor titular del Curso de Cirugía Pediátrica, UNAM

*** Profesor adjunto del Curso de Cirugía Pediátrica, UNAM

**** Endoscopia Pediátrica. Hospital del Niño "Dr. Rodolfo Nieto Padrón" S.S.A. Villahermosa, Tabasco. México.

Correspondencia: Dr. José David Palmer-Becerra. Calle Corone Gregorio Méndez Magaña \# 2832, Colonia Atasta. CP 86110. Tel (993)3 511090 ext. 1055 Villahermosa, Tabasco. México. E-Mail: drjosepalmer@hotmail.com

Recibido: noviembre, 2009. Aceptado: enero, 2010.

Este artículo debe citarse como: Palmer-Becerra JD, MontalvoMarín A, Uro-Huerta $\mathrm{H}$ y col. Malformacion congénita de la vía aérea pulmonar. Informe de un caso y revisión de la literatura. Acta Pediatr Mex 2010;31(2):70-74

www.nietoeditores.com.mx ca congénita a "malformación congénita de la vía aérea pulmonar" la cual divide en cinco tipos, basado en la apariencia macroscópica y microscópica de los componentes hamartomatosos de la lesión con las múltiples áreas del tejido traqueo-bronquial normal ${ }^{1}$.

Se piensa que esta malformación se debe a un defecto en el cambio del periodo canalicular al de saco terminal ${ }^{2}$. Afecta principalmente a los lóbulos inferiores y predomina el derecho (80\%). Los síntomas principales son polipnea, dificultad respiratoria progresiva y cianosis que pueden iniciarse desde el periodo neonatal hasta el primer año de vida en el $90 \%$ de los casos. En niños mayores, son frecuentes las infecciones pulmonares y pueden ser el primer signo de una malformación congénita de la vía aérea pulmonar. En ocasiones la malformación es asintomática y el diagnóstico se sospecha al detectar hipoventilación durante la auscultación o por anormalidades visibles en una radiografía de tórax. La tomografía computarizada de tórax con medio de contraste confirma el diagnóstico. El tratamiento de elección es la lobectomía ${ }^{3}$. 


\section{CASO CLINICO}

Niña de tres meses de edad, enviada por el Servicio de Neumología Pediátrica con diagnóstico de malformación pulmonar congénita sospechada por una radiografía de tórax. Producto de una madre de 29 años de edad, primigesta, embarazo normoevolutivo sin complicaciones. Un ultrasonido obstétrico a las 22 semanas de gestación mostró imágenes de un quiste pulmonar del lóbulo superior izquierdo, sin aporte sanguíneo anómalo (aorta) que lo nutra. Por el antecedente de la malformación pulmonar la niña nació por cesárea, a término. Pesó 3,100 g; no tuvo asfixia perinatal ni sintomatología respiratoria. La radiografía de tórax al nacimiento mostró una imagen hiperlúcida pequeña en el lóbulo superior izquierdo. Debido a la ausencia de síntomas fue egresada del hospital. A los tres meses de edad, acude a control pediátrico; la radiografía de tórax mostró una imagen en el hemitórax superior izquierdo, redondeada, hiperlúcida, con escaso parénquima pulmonar, que desplaza las estructuras del mediastino hacia la derecha (Figura 1). Una tomografía de tórax permitió identificar tres imágenes ovoides en el lóbulo superior izquierdo, la mayor de aproximadamente 7.7 x $4.1 \mathrm{~cm}$ con -994 UH (Figura 2), lo que hizo sospechar una malformación congénita de la vía aérea pulmonar. Se decidió realizar una toracotomía posterolateral izquierda.

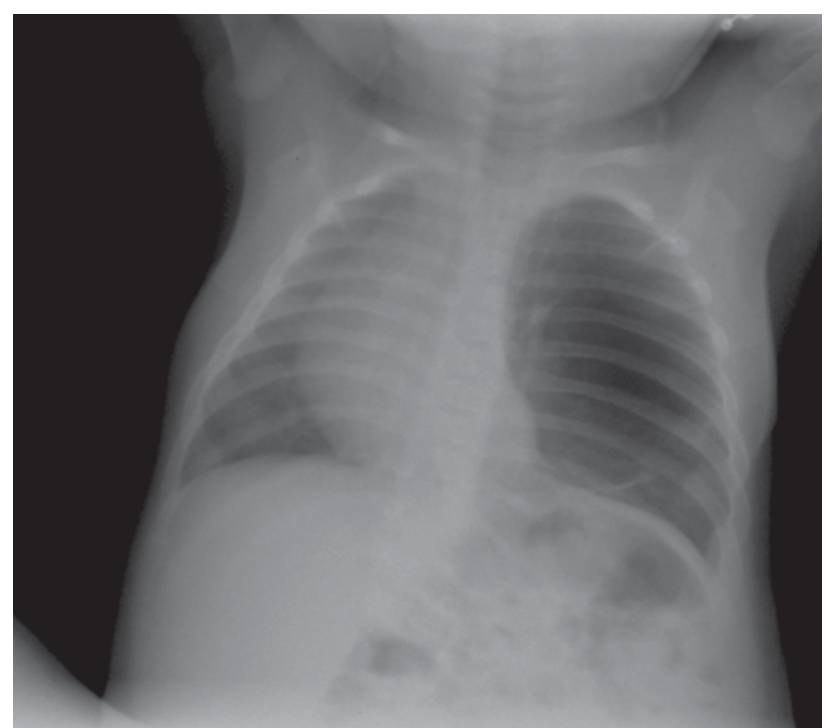

Figura 1. Radiografía de tórax que muestra del lado izquierdo una lesión quística, bilobulada, hiperlúcida, que desplaza las estructuras del mediastino al hemitórax derecho.

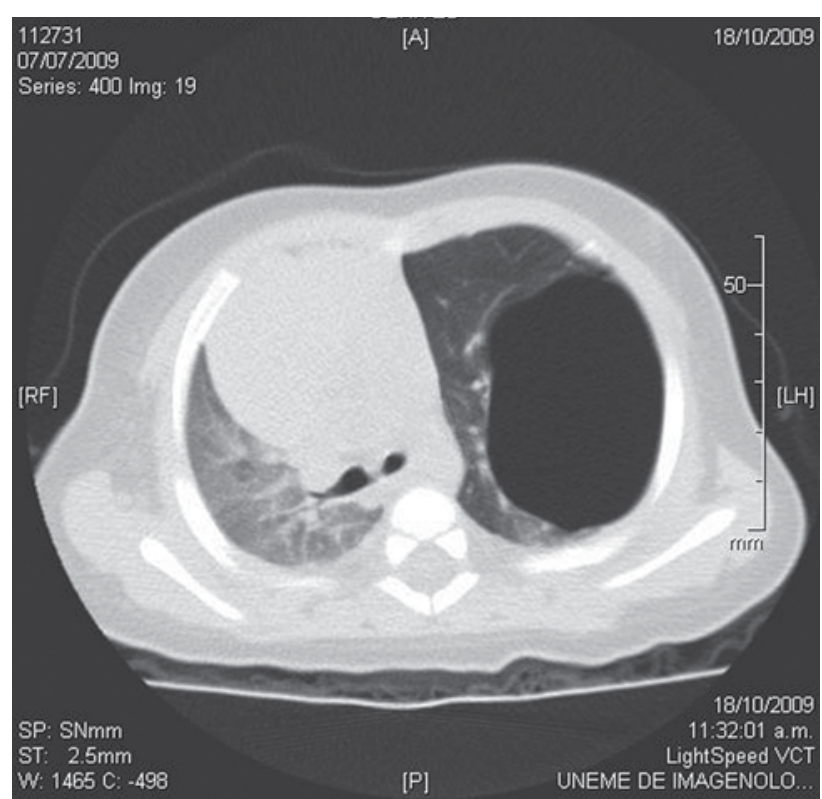

Figura 2. Tomografía computarizada. Muestra una imagen quística y redonda, que sólo contiene aire en hemitórax izquierdo, el resto del tejido pulmonar se encuentra comprimido y desplaza el mediastino al lado contralateral.

Se identificó una lesión quística, grande, en todo el lóbulo superior izquierdo, de aspecto pálido, lleno de aire, con herniación hacia el lado contralateral; el lóbulo inferior izquierdo tenía aspecto hipoplásico (Figura 3). Se realizó lobectomía superior izquierda. El estudio anatomopatológico diagnosticó que la masa estaba compuesta por un gran quiste $(5 \times 4 \mathrm{~cm})$ que ocupaba $60 \%$ del lóbulo resecado y concluyó que era una malformación congénita de la vía aérea pulmonar tipo 1 de la clasificación de Stocker (Figura 4). La paciente evolucionó favorablemente. El antibiótico (cefotaxima) se suspendió a las 48 h del evento quirúrgico. Inició la alimentación a las 48 h. Se retiró la sonda pleural al tercer día, cuando una radiografía de tórax mostró reexpansión del 75\% del hemitórax. Egresó al sexto día del postoperatorio sin complicaciones.

\section{DISCUSION}

La embriogénesis pulmonar es un proceso complejo. La formación del esbozo pulmonar a partir de la cuarta semana de gestación es producto de una evaginación del intestino anterior. Este esbozo da origen al tubo laringotraqueal de donde se desarrollarán la laringe, la tráquea, los bronquios y los pulmones. El endodermo se encarga de formar el epitelio de revestimiento; el mesénquima esplácnico, el 


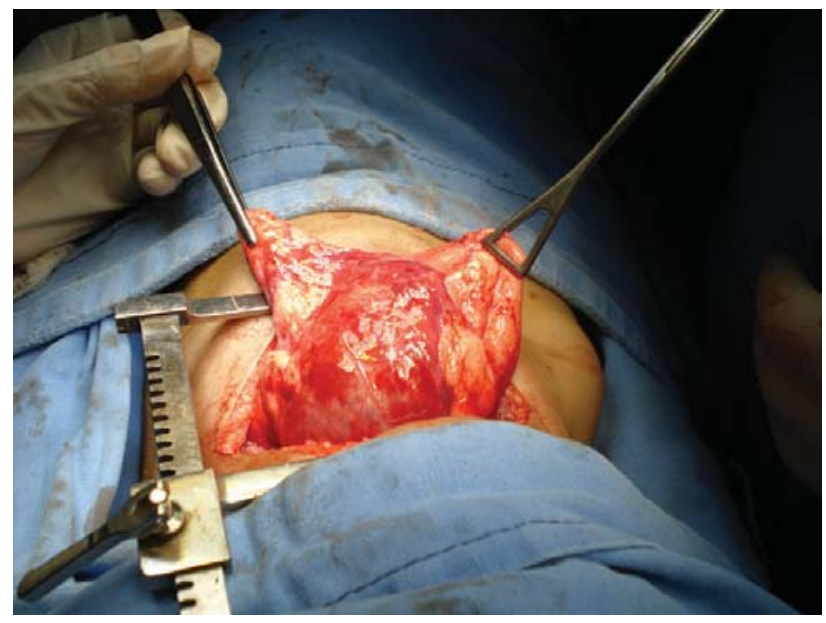

Figura 3. Fotografía tomada durante el evento quirúrgico. Al realizar una toracotomía posterolateral izquierda se exteriorizó el pulmón y se observó una gran lesión quística adherida al parénquima pulmonar del lóbulo inferior izquierdo.
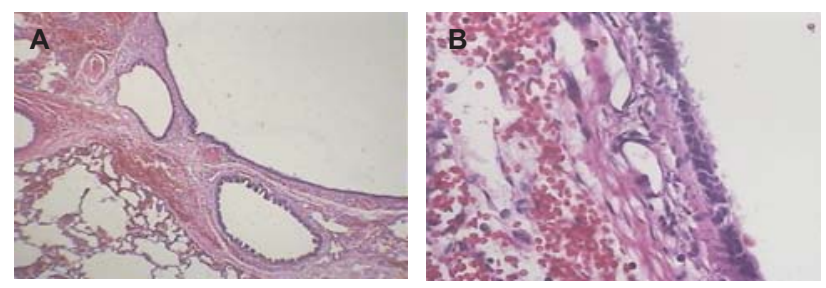

Figura 4. Microfotografía con tinción de hematoxilina y eosina. Se observa la pared delgada del quiste, con pequeños quistes a su alrededor y con tejido pulmonar adyacente comprimido, además del epitelio cilíndrico seudoestratificado.

tejido conectivo, cartílago y músculo. Las dos yemas o esbozos broncopulmonares se desarrollan a partir del tubo laringotraqueal en la quinta semana de gestación; en la yema derecha aparecen dos yemas secundarias y en la yema izquierda aparecen tres, que luego se dividirán por dicotomía. Cada yema crece en dirección caudal y lateral, introduciéndose en la cavidad celómica; así formarán la cavidad pleural primitiva. La pleura visceral deriva del mesodermo esplácnico y la pleura parietal del mesodermo somático. Cada periodo de desarrollo del parénquima pulmonar ocurre por etapas, concluyendo en el alveolar, que se produce desde el nacimiento hasta los ocho años de edad, cuando el epitelio pulmonar se aplana y aumenta el número de alvéolos ${ }^{4}$. La malformación congénita de la vía aérea pulmonar se define como una lesión hamartomatosa de las estructuras bronquiolares a expensas de los alvéolos.
Esta afección congénita pulmonar se debe a una alteración del componente epitelial de la yema bronquial, ocasionando sobrecrecimiento de estructuras bronquiales y disminución de alvéolos. Es la malformación broncopulmonar congénita más frecuente: $95 \%$ de los casos. Ocurre en 1 de cada 5,000 a 20,000 recién nacidos vivos ${ }^{5}$. La clasificación más reciente y aceptada hace hincapié sobre los hallazgos clínicos, criterios macroscópicos y microscópicos, así como la región anatómica donde se origina el defecto, y se mencionan a continuación:

Tipo 0: De origen traqueo-bronquial, también conocido como agenesia o displasia acinar; es incompatible con la vida. Puede ocurrir en prematuros que presentan cianosis a las pocas horas de vida. Macroscópicamente los pulmones son pequeños y tienen superficie granular. Microscópicamente el tejido consiste en múltiples estructuras bronquiales con músculo, glándulas y cartílago.

Tipo 1: De origen bronquial y bronquiolar. Es el más común (65\%). La manifestación clínica al nacimiento es la polipnea; en el niño mayor, la dificultad respiratoria y las infecciones frecuentes. Macroscópicamente se ven quistes grandes que miden de 3 a $10 \mathrm{~cm}$ de diámetro, en su alrededor se encuentran quistes pequeños y parénquima pulmonar comprimido. Microscópicamente los grandes quistes tienen epitelio columnar seudoestratificado, ciliado y más del $45 \%$ de estas lesiones contiene células productoras de moco, que se han relacionado con la transformación maligna a carcinoma broncoalveolar.

Tipo 2: De origen bronquiolar. Es el segundo tipo más común (15\%). Las manifestaciones clínicas aparecen en el primer año de vida; se acompaña de agenesia renal y malformaciones cardiovasculares; tiene mal pronóstico. Los quistes miden de 0.5 a 2 cm de diámetro; se encuentran unidos a parénquima pulmonar normal. Se ven en el 50\% de los secuestros extralobares.

Tipo 3: De origen bronquiolar-bronquiolo respiratorio. Son quistes pequeños que ocurren en el 5\% de los casos; predominan en varones; se asocian a polihidramnios materno y anasarca fetal. Macroscópicamente miden menos de $0.2 \mathrm{~cm}$ de diámetro. Microscópicamente corresponden a conductos alveolares con una cubierta epitelial y un intersticio con pocas arterias alveolares. El pronóstico es malo.

Tipo 4: Es de origen acinar. Se presenta con dificultad respiratoria desde el nacimiento, neumonía y neumotórax a tensión. Macroscópicamente tienen pared delgada y se 
ubican en la periferia del lóbulo pulmonar. Microscópicamente se observa un epitelio cuboidal con múltiples arterias y arteriolas en el mesénquima ${ }^{6}$. La sintomatología depende del momento del diagnóstico, que puede cursar con hidrops en la etapa fetal: derrame pericárdico, derrame pleural, ascitis, líquido libre anormal en alguna parte del organismo o con polihidramnios materno o placentomegalia. Lo habitual en el recién nacido es la dificultad respiratoria y problemas para la alimentación. En el niño mayor puede ser la polipnea e infecciones respiratorias recurrentes ${ }^{7}$.

Los estudios diagnósticos para evaluar a un paciente con una masa torácica congénita son de dos tipos:

1) Periodo fetal: Recientemente se ha logrado calcular por ultrasonografía (US), el volumen/radio del quiste pulmonar, dividiendo la forma ovoide del quiste (longitud $\mathrm{x}$ peso $\mathrm{x}$ ancho $\mathrm{x}$ 0.52) entre el perímetro cefálico fetal. Con esta fórmula se logra conocer el peso aproximado; este cálculo se puede complementar midiendo la longitud de la masa y el diámetro del hemitórax. Un resultado de 1.6 o mayor, es altamente predictivo de desarrollo de hidrops fetal en un $80 \%$ de los casos. Por lo de más este estudio identifica una masa intratorácica, revela si es unicameral o multicameral; delimita las dimensiones, la presencia de líquido en tórax, pericardio, abdomen o alguna otra región anatómica. Permite definir lesiones macroquísticas cuando un quiste o múltiples quistes miden $5 \mathrm{~mm}$ o más de diámetro y microquísticas cuando son menores de $5 \mathrm{~mm}$.

La resonancia magnética fetal, muestra la distribución de los vasos hiliares, revela la presencia de arterias aberrantes para descartar un secuestro pulmonar y delimita los quistes pulmonares ${ }^{8}$.

2) Periodo neonatal: La radiografía de tórax puede mostrar una lesión hiperlucida, quística, uni o multilobulada, con nivel hidroaéreo y desplazamiento del mediastino. Una tomografía computarizada con medio de contraste, puede revelar lesión quística con nivel hidroaéreo en su interior; con paredes delgadas que desplaza las estructuras hacia el lado sano. Un gammagrama pulmonar muestra un lóbulo funcional excluido.

El diagnóstico diferencial debe realizarse con una hernia diafragmática congénita, secuestro pulmonar, quiste broncogénico, teratoma mediastinal, enfisema lobar congénito y duplicación intestinal ${ }^{9}$. El diagnóstico de certeza se obtiene con el estudio histopatológico. Macroscópicamente se observa la lesión quística con paredes trabeculadas y quistes a su alrededor; microscópicamente se apreciará un epitelio ciliado, seudoestratificado con células columnares y algunas secretoras de moco pero esto dependerá del tipo histológico según la clasificación de Stocker. El tratamiento de las malformaciones congénitas de la vía aérea pulmonar debe ser interdisciplinario, con médicos a cargo del paciente que deben estar involucrados desde el inicio en la valoración preanestésica, la intubación bronquial selectiva; los cirujanos pediatras experimentados y el manejo postquirúrgico en una terapia intensiva.

Se han publicado casos de regresión espontánea. El uso de esteroides (betametasona $12.5 \mathrm{mg}$ intramuscular) ha dado respuestas variables y resultados poco alentadores ${ }^{10}$. El tratamiento siempre es quirúrgico. En el periodo fetal puede realizarse una derivación toracoamniótica, aspiración del quiste o una cirugía fetal abierta en un intento de salvar la vida si existe hidrops fetal y hay compromiso del sistema cardiovascular ${ }^{11}$

En recién nacidos sintomáticos, la lobectomía no debe demorarse. En pacientes asintomáticos se prefiere una vigilancia estrecha y decidir la cirugía en un tiempo posterior. Cuando existen problemas respiratorios como neumonía, abscesos pulmonares o neumotórax, la estancia hospitalaria es mayor que en pacientes asintomáticos ${ }^{12}$ por este motivo, se realiza una lobectomía al resolver un proceso infeccioso ${ }^{12}$. Actualmente, la resección pulmonar con procedimientos de mínima invasión (toracoscopia) es el método más efectivo para tratar las malformaciones pulmonares congénitas en pacientes asintomáticos; y éstos se deben operar por el riesgo de complicaciones como infecciones pulmonares recurrentes, neumotórax, hemoptisis y malignización de la lesión; la edad ideal para intervenir es entre los seis y 18 meses de edad, por la menor morbilidad, de complicaciones como la insuficiencia respiratoria, el neumotórax postquirúrgico y el empiema pleural ${ }^{13}$. Cuando los pacientes tienen una presentación atípica como sucede en niños mayores, neumonías recurrentes y trastornos de la función pulmonar, el abordaje quirúrgico de elección es la toracotomía abierta ${ }^{14}$. Las complicaciones postoperatorias son la escoliosis (por la toracotomía) en el periodo fetal o neonatal, y la lesión pulmonar congénita residual que se sospecha en niños intervenidos previamente que en el postoperatorio persisten con infecciones respiratorias crónicas y anormalidades visibles en estudios radiológicos. La tomografía computarizada con medio de contraste es de gran ayuda en estos casos ${ }^{15}$. El pronóstico por lo ge- 
neral es bueno. El diagnóstico prenatal y la intervención quirúrgica temprana es segura y reduce notoriamente la morbilidad y mortalidad.

\section{BIBLIOGRAFIA}

1. Stocker JT. Congenital pulmonary airway malformation: a new name for an expanded classification of congenital cystic adenomatoid malformation of the lung. Histopathology. 2002; 41(supplement 2): 424-30.

2. Rodgers BM, Harman PK, Johnson AM. Bronchopulmonary foregut malformations. Ann Surg. 1986;203:517-24.

3. Black TL. Pulmonary sequestration and congenital cystic adenomatoid malformations. In: Ziegler MM, Azizkhan RG, Weber TR (eds): Operative pediatric surgery. Philadelphia: W.B. McGraw-Hill; 2003.

4. Sadler TW. Embriología médica con orientación clínica. 9a. edición. Buenos Aires: Médica Panamericana; 2004. p. 28999.

5. Wang NS, Chen MF, Chen FF. The glandular component in congenital cyst adenomatoid malformation of the lung. Respirology. 1999;4:147-53.

6. Stocker JT. The respiratory tract. In: Stocker JT, Dehner LP. Pediatric pathology. 2nd ed. Philadelphia: Lippincott W\&W; 2002. p. 445-517.

7. Adzick NS, Farmer DL. Cysts of the lungs and mediastinum. In: Grosfeld JL, O’Neill JA, Fonkalsrud EW, Coran AG. Pediatric surgery. 6th ed. St. Louis: Mosby; 2006. p. 955-70.
8. Vu L, Tsao K, Lee H, Nobuhara K, Farmer D, Harrison M, Goldstein R. Characteristics of congenital cystic adenomatoid malformations associated with nonimmune hydrops and outcome. J Pediatr Surg. 2007;42:1351-6.

9. Smith M, Samuel M, Lees C, Set P, D'Amore A. Congenital pulmonary malformations associated with esophageal duplication and teratoma: prenatal to postnatal management. J Pediatr Surg. 2008;43:E31-E33.

10. Morris LM, Lim FY, Livingston JC, Polzin WJ, Crombleholme TM. High risk fetal congenital pulmonary airway malformations have a variable response to steroids. J Pediatr Surg. 2009;44:60-65.

11. Grethel EJ, Wagner AJ, Clifton MS, et al. Fetal intervention for mass lesions and hydrops improves outcome: a 15-years experience. J Pediatr Surg. 2007;42:117-23.

12. Aziz D, Langer JC, Tuuha SE, Ryan G, Ein SH, Kim PC. Perinatally diagnosed asymptomatic congenital cystic adenomatoid malformation: to resect or not? J Pediatr Surg. 2004;39(3):32934.

13. Truitt AK, Carr SR, Cassese J, Kurkchubasce AG, Tracy TF, Luks FI. Perinatal management of congenital cystic lung lesions in the age of minimally invasive surgery. J Pediatr Surg. 2006;41:893-96.

14. Vu LT, Farmer DL, Nobuhara KK, Miniati D, Lee H. Thoracoscopic versus open resection for congenital cystic adenomatoid malformation of the lung. J Pediatr Surg. 2008;43:35-39.

15. Phaloprakarn C, Pott EM, Harrison MR. Residual congenital cystic adenomatoid malformation and thoracic scar deformation after fetal surgery: a case report. J Pediatr Surg. 2006;41:E11-E14.

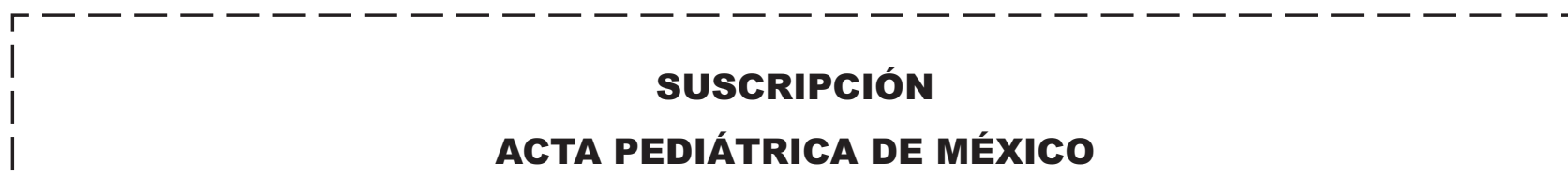

Suscripción anual (6 números): $\$ 350.00$ (trescientos cincuenta pesos)

Nombre:

Dirección:

Colonia: Estado:

Código postal:

País:

Teléfono:

Depósito en la cuenta 4030985774 del Banco HSBC.

Enviar ficha de depósito, en un plazo no mayor de 20 días, a: Publicaciones Médicas. Instituto Nacional de Pediatría. Insurgentes Sur 3700 C, Col. Insurgentes Cuicuilco, México, DF 04530. Tel.: 1084-0900 ext. 1112 y 1489.

- - - - - - - - - - - - - - - - - - - - - - - 